\title{
Desenvolvimento e Aplicação de Metodologia para a consolidação do Fórum de Editores e Comunicação Científica da UFF
}

\author{
Methodology Development and Application for the consolidation of the Editors \\ and Scientific Communication Forum from UFF
}

\author{
Sofia Albuquerque \\ Mestre em Sociologia \\ Universidade Federal Fluminense \\ sofialbuquerque@gmail.com \\ Thaiane de Oliveira \\ Doutora em Comunicação Social \\ Universidade Federal Fluminense \\ thaianeoliveira@id.uff.br
}

\section{Resumo}

A proposta deste artigo é registrar o processo de consolidação do Fórum de Editores e Comunicação Científica (Foco) da Universidade Federal Fluminense, buscando compartilhar a experiência e metodologias adotadas para a construção de um espaço coletivo para promover a melhoria do impacto e da circulação científica dos periódicos da universidade. Trata-se de um relato de experiência que tem como proposta apresentar os procedimentos, desafios e resultados obtidos até então, bem como debater as ações futuras do Fórum junto ao público, sobretudo com outros coordenadores de Fórum de Editores.

Palavras-chave: Fórum de Editores. Metodologia. Impacto.

\begin{abstract}
The purpose of this poster is to record the consolidation process of the Fluminense Federal University's Editors and Scientific Communication Forum, seeking to share the experience and methodologies adopted for the construction of a collective space to promote the improvement of the impact and the scientific circulation of university journals. This is an experience report, which proposes to present the results obtained so far, as well as to discuss future actions with the public, especially other coordinators of the Editors' Forum.
\end{abstract}

Keywords

Editors Forum. Methodology. Impact.

doi: $10.28998 /$ cirev.2020.7ne.23-31

Esta obra está licenciada sob uma Licença Creative Commons.

Submetido em: 19/03/2020

Aceito em: 23/03/2020

Publicado em: 30/03/2020 


\section{INTRODUÇÃO}

O que é preciso para sermos ouvidos? O que é preciso para que as nossas pesquisas alcancem o maior número de pessoas dentro da comunidade científica e, conforme ambicionamos, para que ultrapassem as fronteiras das universidades e dos centros de pesquisa? Recentemente a ciência ganhou maior relevância como pauta política. A última eleição para o Poder Executivo Federal trouxe um agrupamento de figuras que, explicitamente, demonstrou o seu descontentamento com o meio acadêmico. Discursos amistosos acompanharam a inserção de figuras políticas explicitamente anticientíficas no cenário das políticas públicas ${ }^{1}$. Como consequência, sofremos com cortes de gastos, redução de bolsas e precarização dos serviços. Nesse contexto, a presente pesquisa ganhou relevância estratégica.

Em 2017 começamos a desenvolver a pesquisa que deu origem a este artigo com um interesse prático específico: a criação de um direcionamento estratégico para ampliar o alcance dos periódicos científicos da Universidade Federal Fluminense (UFF). A partir deste ponto inicial, escolhemos direcionar a pesquisa por dois enfoques distintos. O primeiro consistiu na reavaliação dos critérios de qualidade dos periódicos, e o segundo, no aperfeiçoamento da gestão das revistas científicas a partir dos recursos disponíveis.

No que se refere às modalidades de difusão do conhecimento, Wilson Bueno (2010) distingue divulgação e comunicação científica. De acordo com o autor, a primeira tem como principal alvo o público leigo, pessoas que não têm fluência nas terminologias científicas e que, tampouco, têm proximidade com os autores e bases teóricas utilizadas nas pesquisas divulgadas. A comunicação científica, por outro lado, visa atualizar os próprios cientistas das descobertas feitas nas áreas em que estão inseridos. Consideramos que as duas modalidades de difusão do conhecimento estão profunda e intrinsecamente associadas à prática científica. Todavia, nesta pesquisa daremos enfoque especial aos veículos de comunicação científica.

Este artigo se insere em um contexto de ciência periférica ocupado pelos centros de pesquisa e divulgação científica latino-americanos e, mais especificamente, brasileiros (ENGELMANN, 2008). Esse contexto é reforçado pela construção de um imaginário que reforça a fragilidade dos periódicos locais em veicular artigos de relevância internacional (VESSURI; GUÉDON; CETTO, 2014).

Pesquisadores periféricos têm se esforçado para denunciar esta desigualdade (BEIGEL, 2013). Todavia, consideramos que a análise e a denúncia da condição desigual dos pesquisadores brasileiros deve ocorrer em conjunto com a formulação e a consolidação de políticas públicas em âmbito nacional. $\mathrm{O}$ ato de fazer ciência só faz sentido quando divulgado, discutido e aperfeiçoado; quando as nossas vozes ecoam e encontram interlocutores. Essa é a função do Fórum de Editores e Comunicação da UFF (Foco), criado pela Pró-reitoria de Pesquisa, Pós-graduação e Inovação (Proppi) com o propósito de assessorar assuntos relacionados aos periódicos dos Programas de Pós-Graduação Stricto Sensu. Assim, o Fórum assumiu, em 2016, as funções de apoiar intercâmbio de informações e experiências entre os editores de periódicos da UFF e assessorar na formação e implementação da política editorial dos periódicos vinculados aos respectivos programas.

A partir das funções institucionais do fórum, foi criado um grupo de pesquisa com o objetivo de preencher a lacuna na produção de conhecimentos referente aos periódicos nacionais. No Brasil, os periódicos são "financiados quase que exclusivamente com recursos públicos" (ORTELLADO, 2008) e surgem, majoritariamente, de forma descentralizada no interior dos

1 O ministro da Educação, Abraham Weintraub, afirma que irá reduzir as verbas de universidades que não se preocupam com a melhoria dos indicadores científicos porque estão fazendo "balbúrdia". Todavia, não compartilha com a comunidade os critérios de desempenhos utilizados para categorizar a Universidade Federal Fluminense, a Universidade de Brasília e a Universidade Federal da Bahia, indicadas como aquelas que estariam utilizando recursos públicos para fins não científicos. Disponível em: https://veja.abril.com.br/brasil/universidades-com-balburdia-terao-verbas-reduzidas-diz-weintraub/. Acesso em: $16 / 03 / 2020$. 
programas de pós-graduação das universidades públicas para preencher as necessidades dos grupos de pesquisa em ter um ambiente de troca acadêmica, gerido e orientado para as especificidades das áreas. Essa característica propicia uma diversidade de ambientes de troca ao mesmo tempo que organiza macropolíticas editoriais.

A ausência de ambientes de troca e de diretrizes gerais, assim como de centros de formação de editores, faz com que estes enfrentem problemas comuns em manter a periodicidade dos seus periódicos. Revistas nascem e morrem sem que tenhamos controle dos elementos que permitem a sua continuidade. Cientes das limitações dessa abordagem inicial, que esteve restrita a um grupo de periódicos da UFF, o objetivo desta pesquisa é ajudar a entender as dificuldades dos editores científicos com o objetivo de podermos consolidar as políticas públicas na área a partir de elementos concretos da realidade editorial, relatando o processo de consolidação do Fórum de Editores e Comunicação Científica da UFF.

\section{CONSTITUIÇÃO DO FÓRUM DE EDITORES E COMUNICAÇÃO CIENTÍfFICA DA UFF}

Por meio de um projeto junto à Fundação Euclides da Cunha (FEC), o Fórum de Editores e Comunicação Científica da UFF foi fundado em outubro de 2016, com o objetivo de assessorar a Coordenação Stricto Sensu da Proppi em assuntos relacionados à Comunicação Científica e periódicos desenvolvidos pelos Programas de Pós-graduação Stricto Sensu.

Assim, as atribuições do Fórum são:

I. Assessorar a Pró-reitoria de Pesquisa, Pós-graduação e Inovação (Proppi) na formulação e implementação da política editorial dos periódicos vinculados aos programas de pósgraduação Stricto Sensu da UFF;

II. Colaborar na construção e manutenção do Portal de Periódicos da UFF;

III. Desenvolver atividades de capacitação dos editores de periódicos da UFF;

IV. Assessorar a PROPPI na elaboração de editais, concessão e alocação de recursos destinados pela PROPPI aos periódicos desenvolvidos pela pós-graduação Stricto Sensu na UFF;

V. Apoiar a criação de novos periódicos, a manutenção e adequação dos periódicos e materiais técnico-científicos existentes aos padrões de qualidade definidos pelo Fórum;

VI. Promover ações de visibilidade científica da UFF;

Assessorar a Coordenação de Pesquisa da PROPPI nas demais tarefas de sua competência.

O Foco vem atuando em demandas pontuais durante o processo de migração das revistas científicas da UFF, vinculadas aos Programas de Pós-graduação Stricto Sensu entre outras atividades da esfera da Comunicação Científica, como padronização de dados e ações de divulgação científica. A fim de relatar nossas atividades, relacionamos abaixo o que foi desenvolvido de maio de 2018 a agosto do mesmo ano a partir dos objetivos do Fórum de Editores e Comunicação Científica (Foco - Proppi/UFF).

São objetivos do Foco:

1) Qualificar os editores científicos da UFF;

2) Aderir a padrões internacionais da produção científica e técnico-científica da UFF;

3) Implantar e oferecer suporte operacional ao sistema de editoração de periódicos eletrônicos comumente utilizados pelas revistas da UFF (Portal de Periódicos da UFF);

4) Ampliar áreas de excelência e o impacto social da produção e difusão do conhecimento científico, tecnológico, artístico e cultural, visando aumentar o impacto e a visibilidade da produção científica da UFF. 


\section{DESENVOLVIMENTO DA PESQUISA}

Em 2017, o projeto "Desenvolvimento e aplicação de metodologia para aumento do impacto de publicações científicas do Estado do Rio de Janeiro" foi contemplado com uma bolsa de Inovação Tecnológica pela Faperj, de nível mestrado. Tal proposta tinha como objetivo desenvolver um planejamento estratégico para o Estado do Rio de Janeiro, com foco na UFF, visando melhorar a circulação científica de revistas do estado, aumentando assim o impacto de produção científica do Estado e fornecendo instrumentos para a formulação de políticas públicas científicas mais aderentes à realidade do ambiente científico nacional.

Como uma das etapas iniciais do processo de consolidação e entendimento sobre o perfil das revistas científicas da UFF, identificamos 150 revistas no levantamento inicial dos periódicos científicos da instituição, distribuídos em diferentes servidores, o que dificultava o trabalho de atendimento às demandas editoriais. Todavia, considerável parte dessas revistas foi descontinuada, tinha periodicidade irregular ou, ainda, representava espaços unicamente voltados para a publicação científica discente da própria universidade. Assim, após esse levantamento inicial, foram identificados 38 periódicos de programas de pós-graduação na UFF. Desse número, 13 aceitaram participar da presente pesquisa.

A partir de uma análise qualitativa, reservamos o ano de 2017 para conhecer as especificidades de produção e organização internas dos periódicos científicos selecionados. Por conseguinte, o ano de 2017 foi reservado para conhecer melhor as lógicas de produção dos editores e mapear suas dificuldades e particularidades. Nesse momento inicial nós ambicionamos entender as diferenças históricas (relacionadas à trajetória percorrida por cada um dos periódicos analisados até o momento), organizacionais (relacionadas à organização interna do trabalho dos editores), contextuais (relacionadas às especificidades da área em que o periódico se encontra) e de planejamento (relacionadas à relação entre aquilo que a equipe editorial ambiciona para o futuro da revista o seu efetivo planejamento).

A partir dessas informações elencadas, delineamos as especificidades que existem entre revistas científicas que ocupam diferentes posições no critério Qualis. Tendo em vista esses elementos, conduzimos entrevistas semiestruturadas aplicadas aos editores da UFF.

O roteiro de entrevista visava abranger quatro eixos temáticos diversos. O primeiro eixo esteve voltado à percepção pessoal do trabalho como editor, ou seja, exploramos a figura e a trajetória daquele que é considerado o responsável pela revista. O nosso objetivo foi compreender os diversos critérios de seleção pelas revistas da UFF, ao mesmo tempo que o atrelamos ao engajamento com as atividades da editoração. O trabalho editorial inclui uma enorme abrangência de atividades que são atribuídas de maneiras diferentes a membros também diferentes da equipe editorial.

Concluímos que o trabalho como editor possui diversas interpretações e que, por sua vez, está atrelado a experiências de trabalho muito diversas. Sendo assim, percentual considerável das entrevistas foi aplicado a mais de um entrevistado por revista. Dentre as hipóteses levantadas no decorrer do trabalho, consideramos que a variada quantidade de engajamento por revista pode estar relacionada à sua facilidade de cumprimento com as metas de qualificação. Ou seja, existe uma diferença entre o trabalho do editor individual e o trabalho de uma equipe coletiva de editores.

Ordenamos, no segundo eixo temático, um conjunto de perguntas relacionadas à estrutura da revista. Considerando a existência de diferentes desenvolvimentos e trajetórias, procuramos contemplar os critérios de escolha dos indivíduos que participam da revista desde o processo de captação dos artigos, existência ou inexistência de avaliação por pareceristas, até da seleção de todos aqueles que, direta ou indiretamente, trabalham para que o periódico cumpra todas as atividades no prazo previsto. Além disso, exploramos as questões éticas que permeiam o trabalho de editoração e de publicação.

Os resultados da pesquisa apontaram que o trabalho de editoração era feito por pessoas que, na maioria das vezes, não tem preparo ou formação prévia que lhe atribua o conjunto de 
conhecimentos e experiências necessárias ao gerenciamento de um periódico científico. Sem um conjunto de diretrizes comuns que objetivem uma formação especializada do editor, eles, com frequência, submetem os seus periódicos a práticas com diferentes níveis de eficácia sem garantirem que tal aprendizado institucional seja repassado para as gestões seguintes.

Descobrimos que a formulação das listas de membros do comitê editorial oculta, na sua aparente simplicidade, diversos critérios de seleção, assim como diversas frentes de atuação dentro do processo de editoração. O comitê editorial, composto por membros do corpo docente da pósgraduação a que a revista está atrelada, tem um maior grau de atuação na revista quando comparado com comitês editoriais exógenos. Apesar disso, a exogenia é um dos critérios da Coordenação de Aperfeiçoamento de Pessoal de Nível Superior (CAPES) para que a revista atinja graus de qualificação mais avançados.

Dentre as funções exercidas pelo comitê editorial, podemos citar a avaliação de artigos de autores convidados, além da leitura prévia dos artigos e o seu subsequente envio para os pareceristas. Ademais, alguns editores afirmam que o comitê editorial não exerce nenhuma função prática na revista, exercendo apenas a função simbólica de corroborar para atestar o prestígio da mesma.

No terceiro eixo de investigação olhamos para as políticas de divulgação da revista e a sua inserção nas redes sociais. Percebemos que a maioria das revistas está inserida no Facebook. Os editores utilizam a plataforma para divulgar as principais informações da revista, mas também como uma maneira de ter controle do público que a acessa. Ao mesmo tempo, alguns editores apontaram a existência de uma relação entre o crescimento da página no Facebook e o crescimento da própria revista. Apesar de não ter sido formulado para promover a integração on-line de membros da comunidade científica, o Facebook se mostra, de acordo com os entrevistados, uma ferramenta eficiente para promoção da divulgação e circulação dos seus periódicos. No entanto, a falta de prática e contato com o gerenciamento de redes sociais é posta como um entrave para que a revista interaja mais efetivamente com públicos mais amplos de autores e leitores.

O quarto e último eixo de investigação buscou abrir espaço a fim de que os editores falassem sobre os seus planejamentos para o futuro da revista, e das metas que delinearam com o objetivo de alcançá-lo. Além disso, pedimos que elencassem os suportes que seriam necessários para que os objetivos traçados pudessem ser concretizados. O pedido para a maior capacitação técnica foi um elemento comum em boa parte das entrevistas. A formação acadêmica da maioria dos editores não inclui o manuseamento com as plataformas que a revista está hospedada.

Percebemos que, para muitos editores, o trabalho nas revistas é feito de forma muito experimental e precária. A falta de recursos e de contato entre os editores dentro da Universidade faz com que eles vivenciem problemas muito similares, sem buscar soluções conjuntas para eles. Por isso, os desafios vivenciados nos processos de submissão dos artigos, envio dos mesmos para pareceristas e publicação dentro dos prazos previstos são, em grande medida, constantes. A existência de tantos problemas comuns traz a necessidade da elaboração de um material que atenda às principais dificuldades das revistas das diferentes áreas, mas sem desconsiderar as especificidades de cada proposta editorial.

\section{RESULTADOS}

\subsection{Suportes Técnicos, Institucionais e Financeiros}

Esta categoria da análise das entrevistas se refere aos suportes que são mencionados pelos editores e/ou responsáveis pelo periódico para a sua viabilização prática, ou, em alguns, casos, para a concretização das etapas necessárias à sua melhoria.

A. Falta de Funcionário: 77\% (10 de 13) das entrevistas apresentaram o problema da falta de recursos humanos deslocados exclusivamente para o trabalho editorial. Os editores, como alunos ou professores, apontaram o excesso de atribuições inerentes às suas funções na 
instituição. O excesso de trabalho, somado à ausência de tempo disponível para o volume de trabalho demandado por um periódico científico, seria um elemento impeditivo para a sua melhoria.

B. Problemas Técnicos: 77\% (10 de 13) das entrevistas apresentaram como elemento impeditivo para a melhora da qualidade do periódico os problemas técnicos oriundos do serviço de tecnologia e informação da universidade. Dentre os problemas apresentados podemos destacar a instabilidade do servidor, erros nas plataformas e dificuldade de obter respostas do serviço.

C. Necessidade de Recursos para Tradução: 46\% (6 de 13) das entrevistas apontaram a falta de recursos para tradução dos artigos e/ou resumos submetidos. Enquanto a exigência de submissão de versões em língua estrangeira pode ser um fato impeditivo ao envio de textos por alguns autores para o periódico, a falta total destas versões fere critérios de internacionalização impostos pelos indexadores e por agências de fomento. Assim, os editores/responsáveis indicaram que a universidade poderia fornecer recursos voltados para essa finalidade e/ou criar vínculos com departamentos de letras de forma a viabilizar a tradução dos artigos a serem publicados.

D. Falta de Financiamento: 92\% (12 de 13) apontaram a dificuldade da falta de recursos financeiros para operacionalizar o periódico.

E. Falta de Apoio Institucional: 46\% (6 de 13) indicaram como problema para o desenvolvimento do projeto de periódico científico de qualidade a falta de apoio institucional. Este apoio institucional se refere, em alguns casos, ao suporte do próprio departamento em que a revista está ancorada, mas também ao suporte da universidade enquanto facilitadora de vínculos que podem permitir o funcionamento da revista. Alguns editores/responsáveis indicaram, ainda, que se o apoio institucional fosse maior, a quantidade de recursos necessários para o funcionamento do periódico provavelmente seria inferior do que é requerido atualmente.

F. Dificuldade em indexar a revista: embora parte das revistas esteja nas redes sociais, a indexação é vista como a melhor forma de divulgação do periódico e das suas publicações. Nesse sentido, $54 \%$ (7 de 13) dos entrevistados afirmaram ter dificuldade em cumprir os requisitos das bases indexadoras.

G. Processos de editoração pagos com recursos próprios: 23\% das revistas (3/13) apontaram que pagam ou já pagaram etapas da editoração com recursos de pesquisa ou com recursos pessoais no intuito de contornar a falta de apoio institucional e/ou financeiro.

\subsection{Estímulo profissional da equipe editorial e dos pareceristas: carreira $\mathrm{x}$ caridade}

Este tópico visa trabalhar com a motivação dos editores e pareceristas. Ambas as atividades são encaradas como atividades "extra", exercidas por editores que acreditam no projeto mais do que como atividade profissional, equiparável à docência e à pesquisa.

A. Motivação Acadêmica: em 85\% das entrevistas (11/13), os entrevistados apontaram a motivação acadêmica como aquilo que faz com que permaneçam exercendo o trabalho. Tal motivação está associada ao fato de que eles acreditaram no projeto da revista, na relevância dos periódicos para o programa ou departamento em que está vinculada ou, ainda, na importância científica das revistas acadêmicas.

B. Motivação Profissional: apenas $22 \%$ (5 de 13 ) indicaram a atuação no periódico como uma estratégia profissional de crescimento ou consolidação na carreira.

C. Dificuldade no Trato com Pareceristas: 69\% ( 9 de 13) das revistas apresentaram a dificuldade no trato com os pareceristas, que é um dos desafios do cargo de editor/responsável pela revista e um impeditivo para a adequação à peridiocidade. A dificuldade se refere à baixa taxa de resposta dos especialistas que se encontram na lista de pareceristas e à questão de cumprimento dos prazos. 
D. Reforço de que o trabalho do parecerista é gratuito: 69\% (9 de 13) das entrevistas apresentaram o reforço explícito de que o trabalho dos pareceristas é gratuito, na maior parte das vezes como justificativa para a dificuldade no trato com pareceristas.

\section{3 Ética x desafios práticos: como viabilizar a revista?}

A. Avaliação Diferenciada para Autores Consagrados e Convidados: apenas uma entrevista indicou submeter autores consagrados a avaliações diferenciadas; no entanto, 4 afirmaram avaliar de maneira diferente os autores convidados.

B. Inviabilidade Prática de Submeter ao Duplo Cego: um periódico possui inviabilidade prática de submeter ao duplo cego por conta de dificuldade no trato com pareceristas e domínio das rotinas de trabalho de editor necessárias para tanto.

C. Dificuldade em Manter Periodicidade: 31\% (4 de 13) das entrevistas tiveram menções explícitas à dificuldade de manter a periodicidade.

\subsection{Metas: Estabilidade ou Crescimento?}

A. Estabilidade: 38\% (5 de 13) apresentaram como meta para o Qualis a manutenção da nota que receberam na última avaliação. A estabilidade como meta se justifica pela inviabilidade.

B. Crescimento: o restante dos 62\% (8 de 13) indicaram que planejam aumentar o Qualis atual. No entanto, algumas revistas consideram que, a julgar pelos critérios atuais, é inviável alcançar o status de A1.

C. Perspectivas de Crescimento de Revistas Discente: um dos grupos que tem maior dificuldade de elaborar planejamentos para o alcance das notas máximas do Qualis é composto pelas revistas discentes.

D. Especificidades Temáticas x Regras Gerais de Avaliação: outro grupo que tem dificuldade de se adequar às exigências Qualis é composto por revistas com temáticas muito específicas dentro das suas áreas.

\subsection{Gerenciamento de Revistas: onde aprender?}

Neste tópico trabalhamos com o problema do aprendizado das plataformas que permitem a viabilidade da revista, mas também de expertise de gerenciamento de periódicos científicos.

A. Dificuldade em Aprender a Lidar com Sistemas: mais da metade dos entrevistados ( 7 de 13) indicaram ter dificuldade em lidar com os sistemas relacionados aos periódicos, sendo tal dificuldade um empecilho para usar todas as potencialidades da plataforma.

B. Necessidade de Treinamento de Editores: 31\% dos entrevistados apresentaram que precisam de treinamento para conseguir utilizar as plataformas, indexar e gerenciar o periódico.

\subsection{Como Garantir a Continuidade da Revista - História da Revista}

Neste tópico nos preocupamos com os mecanismos de garantia da continuidade do periódico. Existem periódicos com os mais variados níveis de consolidação que não preveem qualquer processo de substituição dos editores atuais e que correm o risco de morrerem caso estes, por qualquer razão, deixarem de por ele se responsabilizar.

A. Algum Conhecimento da História da Revista: em 77\% das entrevistas, os entrevistados apresentam algum conhecimento da trajetória da revista antes de se assumirem como responsáveis pelo periódico. O que interessa ressaltar é que parte dos que demonstram algum conhecimento da história da revista não tem plena consciência dos erros e acertos 
das gestões anteriores. Em boa parte das entrevistas, o conhecimento da trajetória da revista é parcial.

B. Apresenta sistema que garante a continuidade da gestão da revista: $54 \%$ (7 de 13) das entrevistas demonstraram que o periódico tem algum sistema que garante a substituição dos editores/responsáveis pela revista. O sistema pode ser caracterizado por substituições parciais de equipes editoriais, eleições e seleções internas aos programas/institutos a que o periódico está vinculado.

C. Dificuldade/inviabilidade de manter a continuidade da revista (médio/longo prazo): 4 periódicos (31\%) apresentam grande dificuldade em promover a substituição dos seus responsáveis em um período futuro. Em parte das entrevistas houve a menção explícita de que a revista morreria quando o(s) editor(res) abandonar(em) o projeto.

\section{INICIATIVAS E PERSPECTIVAS FUTURAS DE PESQUISA E INSERÇÃO NA DIFUSÃO CIENTÍFICA BRASILEIRA}

A partir desses resultados, uma série de ações foram conduzidas, buscando assessorar os editores em sua função editorial. Buscando uma qualificação e uma maior reflexão no que consiste a editoração científica, foram realizados dois eventos voltados para este público em 2017: I Workshop de editoração científica em que diversos assuntos foram abordados, entre eles, boas práticas editoriais, comprometimento ético e qualificação da equipe editorial. O segundo, num esforço de aproximação com importantes atores regionais, foi promovido o encontro de editores buscando debater os novos paradigmas da comunicação científica, frente ao intenso processo de metrificação da ciência (WILSDON, 2016) e a ciência aberta.

A partir de 2018, outras ações para promover uma maior segurança aos periódicos da instituição foram realizadas: foi criado o Portal de Periódicos, buscando minimizar os problemas técnicos identificados nas entrevistas. Tal processo está em vias de finalização, após 24 meses de trabalho, marcados pela alta rotatividade no Setor de Tecnologia da Informação da universidade, juntamente com problemas relacionados à crise econômica que as universidades públicas vêm atravessado nos últimos anos. Também em um esforço de melhorar a qualidade e a segurança dos dados digitais, foi fornecido Digital Object Identifier (DOI) para todos os periódicos da Proppi. Neste ano, também foram realizados encontros com editores para discutir e preparar para a indexação em bases de relevância para suas áreas e para a capacitação regular de novos membros do comitê editorial, marcado por uma rotatividade anual, com a entrada de novos estudantes de pósgraduação, que são incentivados a auxiliar no processo editorial, junto aos editores, como parte de suas atividades acadêmicas.

Já o ano de 2019 foi marcado por uma busca de maior participação dos editores. Para isso, são promovidos encontros mensais, nos quais os editores colaboram mutuamente, oferecendo oficinas aos colegas e participando ativamente na consolidação de políticas editoriais na universidade. Neste ano de 2020, pretende-se aprofundar um trabalho de planejamento estratégico, visando aumentar a indexação dos periódicos em bases relevantes para as áreas relacionadas aos periódicos.

A partir dos resultados deste trabalho ambicionamos os seguintes objetivos: aprofundar as orientações para os editores científicos aprimorarem os seus trabalhos nos periódicos e oferecer um treinamento de fácil acesso que, como os nossos entrevistados apontaram, falta para facilitar o manuseio das plataformas, o entendimento sobre as métricas de citação e métricas de circulação e de atenção on-line e efetuar os ajustes necessários para a indexação nas bases almejadas. Tal treinamento está em estruturação e será ofertado por meio de cursos a distância para toda a comunidade científica, não só da universidade, mas também de outras instituições interessadas, como um espaço para troca de experiências e conhecimento, valores prezados pelos editores que participaram dessa pesquisa. 
"O impacto da ciência melhora a saúde, os negócios funcionam melhor, atrai gente, atrai financiamento para pesquisa, atrai pessoas, forma pessoas, melhora políticas públicas", como foi dito por Hernan Chaimovich, presidente do Conselho Nacional de Desenvolvimento Científico e Tecnológico (CNPq), em evento na Sociedade Brasileira para o Progresso da Ciência no mês de setembro de 2019. Mais do que medidas de impacto e indicadores, o que percebemos nesse processo é que os editores precisam de infraestrutura, apoio e reconhecimento de sua função estratégica. Diante de um modelo de acesso aberto, que foi definido a partir de um trabalho que se assemelha ao voluntariado, as revistas científicas brasileiras durante muito tempo se constituíram em torno dessa forma de atuação como uma maneira de se inserir em um cenário internacional competitivo para a produção científica. Porém, esse modelo tem demonstrado sinais de esgotamento, pois, além de recursos cada vez mais escassos, os desafios dos editores se acumulam com outras funções que são demandadas a eles e que também exercem funções de pesquisadores e professores. No horizonte de novas formas de avaliação de CTI, a atividade editorial permanece pouco reconhecida nas avaliações periódicas dos programas de pós-graduação. Sendo esta uma etapa fundamental para o processo de produção de conhecimento, é necessário que as revistas sejam reconhecidas como espaços estratégicos para a comunicação da ciência e parte fundamental no ecossistema científico.

Esperamos que este relato de experiência possa ser útil para outras instituições e outros fóruns de editores, a fim de que possamos compartilhar nossos conhecimentos e nos unir em ações conjuntas para um maior reconhecimento das revistas científicas como espaços estratégicos e necessários à sobrevivência da publicação científica frente aos recursos cada vez mais escassos no horizonte da ciência brasileira.

\section{REFERÊNCIAS}

BEIGEL, M. F. Centros y periferias en la circulación internacional del conocimiento. Nueva Sociedad, v. 245, p. 110-123, maio/jun. 2013.

BUENO, W. C. Comunicação científica e divulgação científica: aproximações e rupturas conceituaiss. Informação \& Informação, v. 15, n. 1esp, p. 1-12, 2010.

ENGELMANN, F. Elites e" instituições" como objeto de estudo numa dinâmica periférica. Teoria \& Pesquisa: Revista de Ciência Política, v. 17, n. 1, 2008.

ORTELLADO, P. As políticas nacionais de acesso à informação científica| National policies for access to scientific information. Liinc em Revista, v. 4, n. 2, 2008.

VESSURI, H.; GUÉDON, J.; CETTO, A. M. Excellence or quality? Impact of the current competition regime on science and scientific publishing in Latin America and its implications for development. Current sociology, v. 62, n. 5, p. 647-665, 2014.

WILSDON, J. The metric tide: Independent review of the role of metrics in research assessment and management. California: Sage, 2016. 